Journal of Business and Management Studies (JBMS)

ISSN: 2709-0876

DOI: $10.32996 / \mathrm{jbms}$

Journal Homepage: www.al-kindipublisher.com/index.php/jbms

\title{
Post-Pandemic Sustainable Business Solution
}

\author{
Kiran Kachela ${ }^{1}$ (D), Suman Lodh ${ }^{2}$ QD and Monomita Nandy ${ }^{3} \mathbb{D} \square$ \\ ${ }^{1}$ Continuous Improvement Projects Ltd, 168 Joel Street, Pinner, London HA5 2PE \\ ${ }^{2}$ Middlesex University, Middlesex University Business School, The Burroughs, Hendon, London, NW4 4BT, UK \\ ${ }^{3}$ Brunel University London, Kingston Lane, Uxbridge, Middlesex UB8 3PH, UK
}

$\triangle$ Corresponding Author: Monomita Nandy, E-mail: monomita.nandy@brunel.ac.uk

\begin{tabular}{ll} 
ARTICLE INFORMATION ABSTRACT \\
\hline
\end{tabular}

Received: February 08, 2021

Accepted: April 22, 2021

Volume: 3

Issue: 1

DOI: $10.32996 / j b m s .2021 .3 .1 .5$

\section{KEYWORDS}

COVID-19; Pandemic; Sustainable

Business Solution; Government

Policy; Resilience; Recovery

Package
In this research, we examined some of the key concerns faced by businesses from various industries which are associated with the COVID-19 pandemic. To extend the existing research, we also evaluate perspectives on sustainable recovery solutions proposed by the business. This market research, supported by academic research, is intended to support businesses and the Government in tapering their approach to achieving sustainable economic recovery. A total of 16 different industries participated in our research project and the findings of our research provide an evidence-based perspective on how businesses are responding to the pandemic and planning for the post-COVID era. This evidence document outlines recommendations on potential support packages and areas of focus for the Government to consider, based on recent survey data, lessons learnt from the past, professional experience and respected academic models.

\section{Introduction}

The COVID-19 (For details about COVID-19 refer to World Health Organisation website https://www.who.int/healthtopics/coronavirus\#tab=tab_1) pandemic has disrupted society and businesses across the globe, presenting extraordinary health, economic and societal challenges (Roubini, 2020). It has proven that economic growth is highly dependent on the development of small business (there is no one definition of small business in practice). In this study, we consider the definition used by the UK HMRC, Company House and Department of Business. A small business is defined as a business with 50 to 500 employees and has a turnover between $£ 6.5$ million and $£ 50$ million. We consider how businesses are interacting with consumer behaviour, the environment, public health, and government policy. There are very few studies focusing on the impact of previous pandemics on a small business model, which limits us to identify the suitable model to follow during and after the coronavirus crisis (Jorda, Singh, \& Taylor, 2020). Thus, it is important to understand which type of interactions between businesses and their stakeholders should take place to generate a dynamic market for the growth of the economy (Jaworski, Kohli, \& Sahay, 2000). In this study, we examine how small businesses are affected by the COVID-19 and what changes they expect during and post-pandemic time. To answer this question a market-based survey was conducted by a London based small business in collaboration with researchers from higher education institutes in the UK. From the literature, we find any business activity will generate economic growth if they are able to create harmony between the person and environment (P-E fit model), which will reduce the cost of business operations and increase the value of the company (Bailey et al., 2017). Such a concept is true for small business. However, the recent pandemic is an unanticipated event, which disturbed the flow of business materials, goods and the existing framework of engagement of people. Businesses who worked hard to identify a system to avoid the adverse impact of any disruption are also affected negatively by the pandemic. Thus, there is an urgent need of identifying the feasibility of the business model in the post pandemic period (Donthu and Gustafsson, 2020). Motivated by the current situation, we examined the research trend in business and management studies related to COVID-19. We find that limited data on COVID-19, motivated researchers to conduct bibliometric analysis to examine the impact of the coronavirus pandemic on business (e.g. Park et al., 2020). However, most of these studies considered a single influential factor in their research domain, which fails to capture the suitability of the business model that can influence the economic growth of the country (Hossain, 2020). Verma and Gustafsson

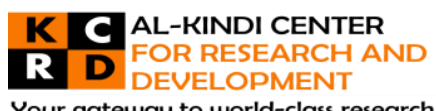

Your gateway to world-class research

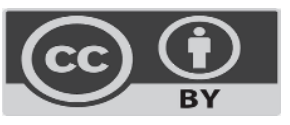

Published by Al-Kindi Center for Research and Development. Copyright (c) the author(s). This open access article is distributed under a Creative Commons Attribution (CC-BY) 4.0 license 
(2020), use the 'Science mapping approach' to define the trend of COVID-19 related research by reducing the subjectivity of a researcher attached with the findings (Bhattacharyya and Verma, 2020). However, in this recent literature, we find a limited detailed discussion about the prevention of disruption created by a previous pandemic or unplanned event like earthquake, hurricane etc. After exploring the disruption prevention literature, we find that that business cannot avoid the negative impact of certain sudden events but they can try to minimise the negative impact by responding sensibly to the economic growth agents on time (Yang and Yang 2010). To extend the existing literature, we conducted a survey to understand the expectation of the one important economic agent, the business to find what they should follow in the post-pandemic time. Following the existing literature, we conducted an online survey as the survey is a technique to understand the opportunities and challenges associated with sustainable economic growth (Nam et al., 2019). The main purpose of the survey is to understand the current areas of concern for businesses and evaluate perspectives on sustainable recovery solutions. We find that in the business recovery package, the respondents are allocating reasonable weights towards the risk and disruption management practices for future sustainable growth.

From the COVID-19 crisis and from our survey, we understand that for the survival of business of any size, it is most important for any business to learn the event properly from start to finish to determine the suitable operational model for economic growth. As business is an important unit of the economy of the country, they need to consider the time-dependent -system-level performance while evaluating their own business level model. Following the conclusion drawn by disruption management, it is clear that business should identify the risk management solutions before planning the disruption management (MacDonald and Corsi, 2013). A business solution where the risk management is followed by disruption management will allow the business to discover the possible negative impact of unplanned events like pandemics at an early stage, which will allow them to reduce the disruption time. This proposed model will support the business to apply the disruption management quite quickly for recovery and redesigning the business activity. See Figure 1.

Figure 1

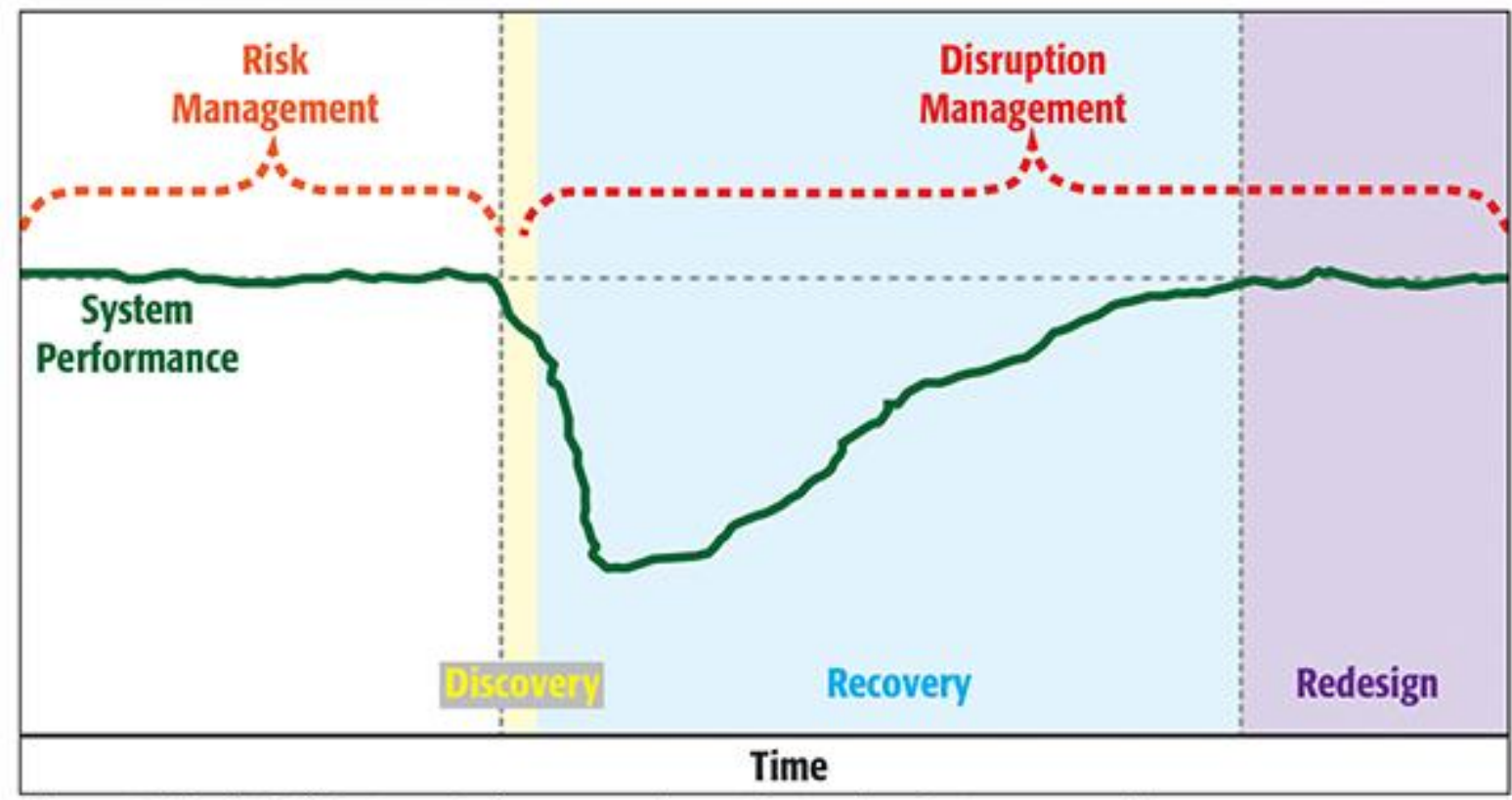

Figure 1. Model of System Performance in an Enterprise System over Time

Source: (MacDonald and Corsi, 2013)

Theoretically, we support the proposed business model (combination of risk management and disruption management) with the revised resilience model, which will allow the business to survive, cope and thrive in future (Tang, 2020). The proposed resilience model will enhance the interaction among the economic agents and can assist the business in rebuilding the growth in the COVID-19 recovery period by enhancing the P-E fit. The practical contribution of the study will enhance the understanding of the business about how to be resilient and combine risk and disaster management which will allow them to find a way to deal with a crisis like the present pandemic. In addition, when companies are resilient, it will be easier for the policymakers to find the most suitable support strategy for business. 
In the remaining paper, first, we summarise the findings form the survey. While summarising the survey findings, we answers four main questions raised by the small businesses for their economic development during the pandemic. In the last section, we highlighted the academic and professional conclusion of the study.

\section{Survey and Key Findings}

\subsection{Sample Description}

The main objective of the survey was to understand how business in different industries have been affected by the COVID-19 crisis and what changes they are expecting in the way they operate. The survey was made public for a period of one month and officially closed at the end of July 2020. In total, we received 122 responses across 16 different industries. The below graphs illustrate the demographics of respondents to the survey. We consider the sample data set to be representative and robust, as the respondents are professionals from all walks-of-life, including small business owners and stakeholders of other small business stakeholders. Figure 2 explain the age of the demographics. In our sample, most of the participants (30.30\%) belongs to the working class in the economy. In Figure 3 we explain the sample on the basis of industry. In total, we have 16 industries, where more respondents are from the education and Business Consulting and management industry.

Figure 2

\section{Survey Demographics by Age}

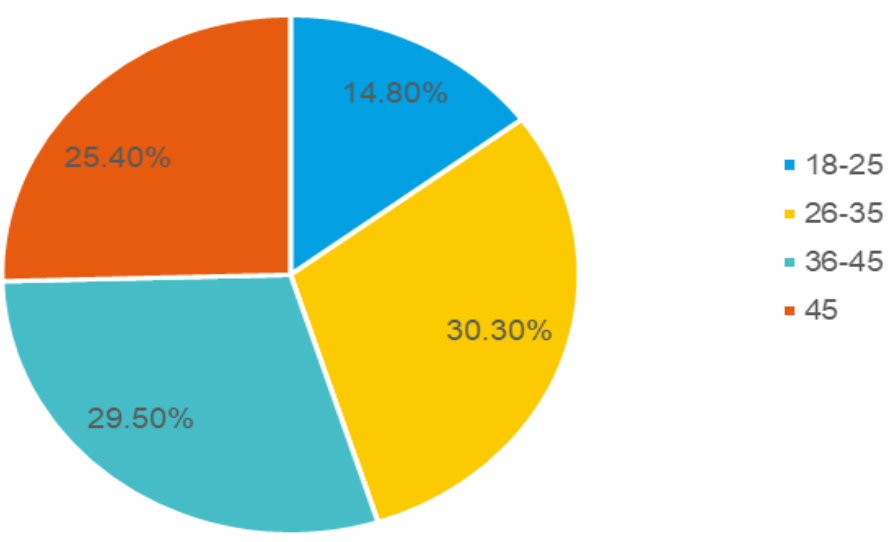

Figure 3

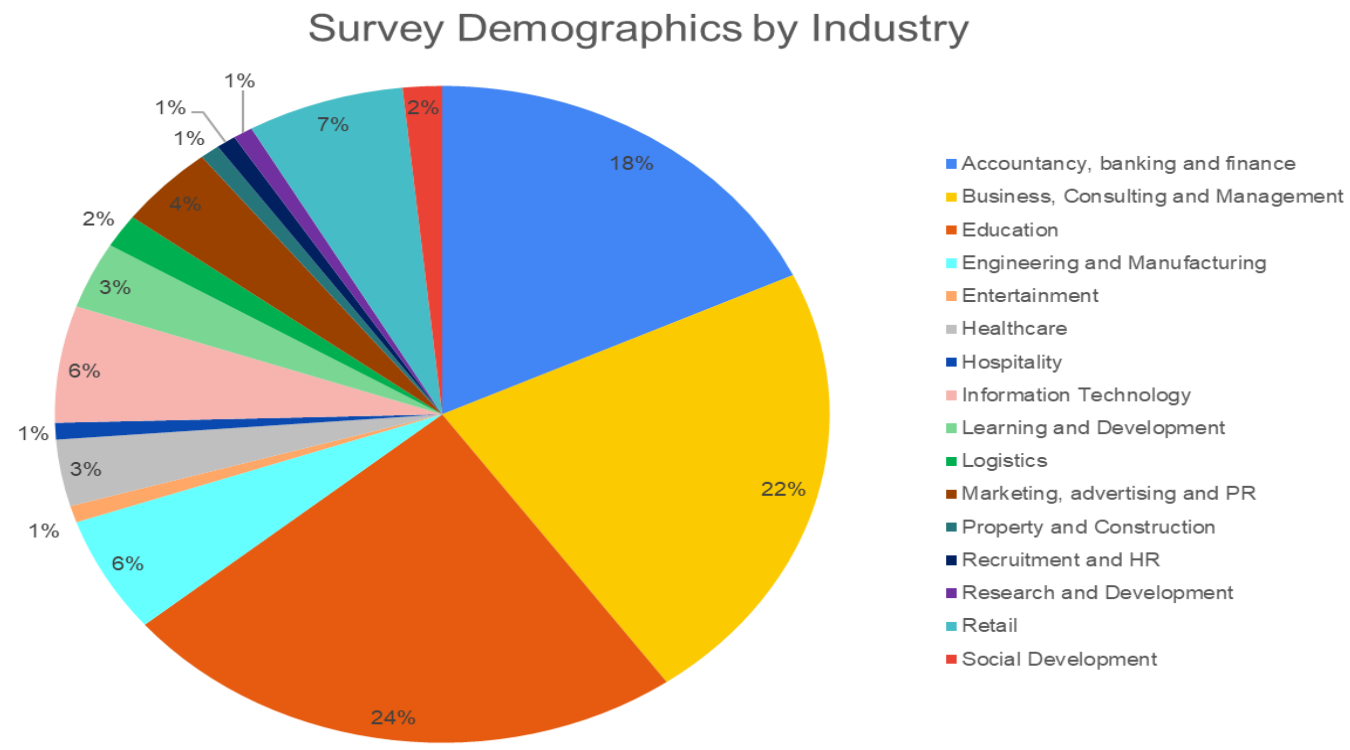




\subsection{Survey Findings and Recommendations for Sustainable Economic Growth 2.2.1 Business expectation about sustainable recovery package}

The main objective of our survey is to understand which factors the businesses want to focus on in the post-COVID-19 time for sustainable growth in their business. From the survey, we develop an understanding of the expectation of business about the government recovery package as there is no clear framework for the small or big business to follow during a pandemic of such extent, so our following findings will extend the existing literature (Jorda, Singh, \& Taylor, 2020) and will assist the policymakers to identify a feasible model to follow in the post COVID-19 time.

From historic crises, there are some key themes that emerge when we look at successful government responses. First and foremost, they prioritise public health and welfare because it's the "right" thing to do and it maintains public confidence. In parallel, economic recovery plans begin to advance early to minimise risk and catastrophic damage. The Government also review and revise policies relevant to the changes that have materialised. Traditionally, these policies have come after the event once changes have unfolded and there is more certainty about the future state. Studies focusing on systematic risk like a financial crisis (We follow Cull and Peria (2013) to define crisis period in this study) or a great depression, (Acharya et al., 2012) mainly focuses on the extreme need for socially optimal capital. The business models managed to understand the importance of certain factors related to social capital; however, these models are hard to apply in the complex situation of pandemic (Thakor, 2015). With these former lessons in mind and the results from our most recent survey, we have developed the following set of guiding principles that should be prioritised in the Government's recovery packages.

Safety first - Sustainable economic recovery is intrinsically dependent on public health; therefore, this principle must remain at the centre of all Government initiatives. According to our survey, $11 \%$ of respondents stated that they will mostly be focusing on safety measures post-COVID-19, including social distancing, increased cleaning frequencies, better risk management and the implementation of better precautionary measures to withstand future crises. A further $4 \%$ cited that they will be prioritising staff wellbeing and safety. These responses came from a variety of industries, demonstrating that safety is a concern for all sectors, not just those that are public-facing. Many organisations have had to invest heavily in essential items to restart business post the lockdown, from fitting out shops with plastic screens to providing hand sanitising stations for customers and employees. Additionally, many shops have had to reduce their stock levels on the shop floor to make room for more social distancing, resulting in reduced sales. Government initiatives need to consider the burden of extra costs incurred by businesses to maintain public safety and support this, as the risk is that struggling businesses may look to reduce costs at the detriment of safety.

Keeping people in employment - Preserving employment levels will avoid deeper economic recession and provide other secondary benefits such as maintaining the physical and mental wellbeing of society, something that could cost the public health system millions if early prevention measures are not instilled. History has shown the devastating and wide-spread impacts of surging unemployment levels. It is predicted that unemployment rates will rocket in the countries despite efforts made by the Government, including the Furlough Scheme and the provision of Bounce Back Loans. In addition to short-term initiatives, like the Furlough Scheme, the Government should consider longer-term solutions such as offering training schemes that will enable skills development and open up new opportunities and consider the relaxation of some policies that have previously been deemed controversial to enable more flexibility for businesses to operate within. Tax schemes should be evaluated to truly understand the impacts on businesses and the economy. Those that may impose negative consequences, such as the IR35 scheme on the self-employed and small businesses, should be re-considered to enable business survival in an already overcrowded and competitive market. The economic pinch amongst businesses across all industries is evident in our survey results, and the consequences of this are already coming to light. For instance, only $2 \%$ of respondents mentioned "new opportunities" and "innovation" when asked what they will focus on most post COVID-19, indicating that the majority of organisations are looking at ways to recover and manage what they already have. Only $3 \%$ of respondents claimed that they would be prioritising marketing in the post-COVID-19 era. With tightened purses, many organisations have had to slash their marketing budgets which will have a knock-on effect on new business development and growth opportunities. References to cost savings, reallocating budgets, transforming target operating models and managing cash flow were all prevalent amongst the responses.

Be a leader - In many of the survey responses received, there was an undertone of passiveness, with a view that businesses would be directed by the guidelines issued by the Government and that their success or failure is in the hands of the Government. We are living in unprecedented times, surrounded by new experiences never encountered before. In times of ambiguity and unpredictability, people look to leaders for direction. The Government needs to appreciate the significance of their role as leaders in the current circumstances and conduct themselves accordingly, taking careful consideration of the language and leadership approaches used.

Pursue technological excellence $-22 \%$ of respondents claimed that they would be prioritising digital solutions in the postCOVID-19 era. This is the most popular focus area selected by respondents, as illustrated in the below graph. 
Figure 4

Which aspects of your business are you going to focus on most post Covid-19?

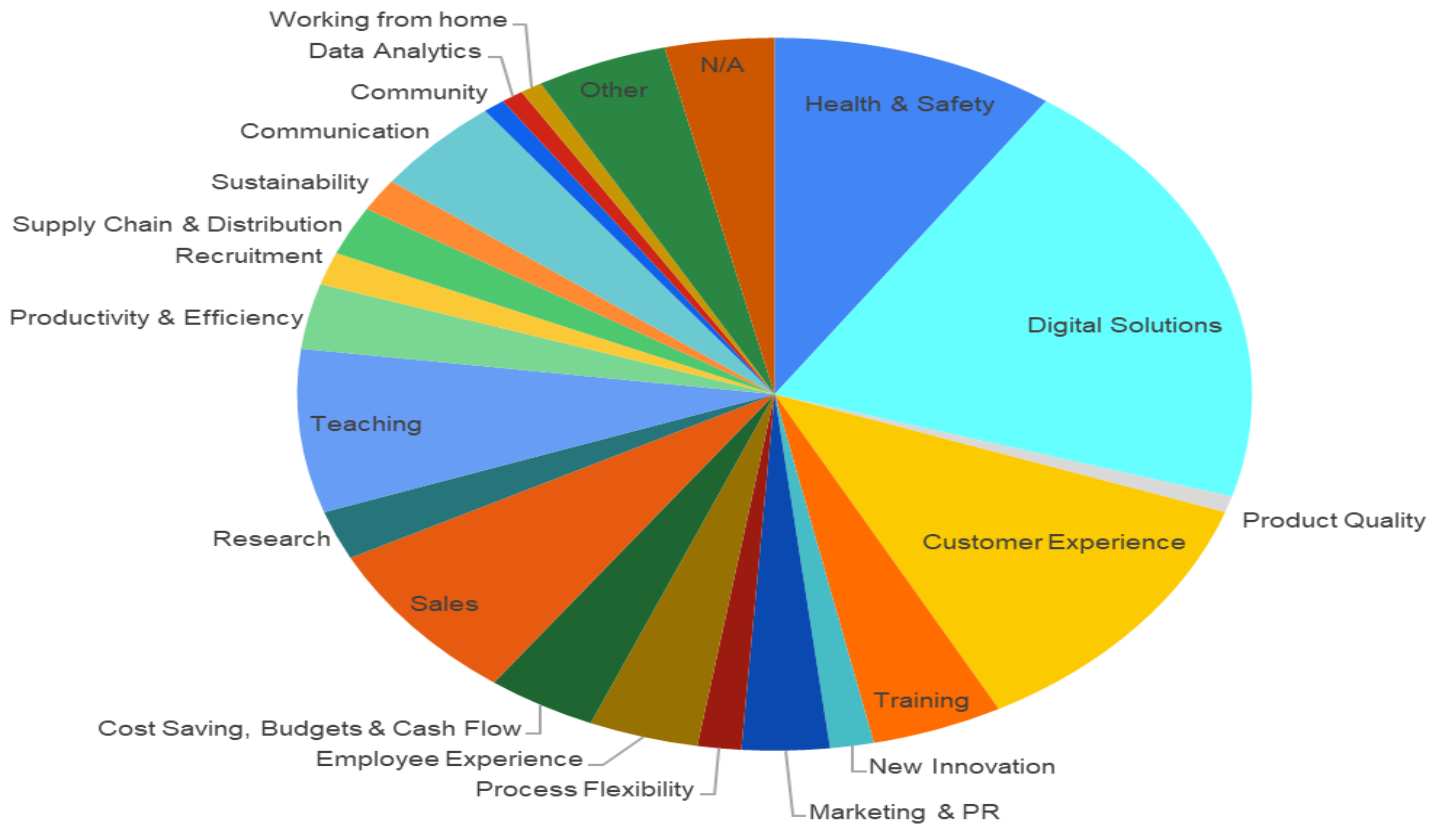

The below graph further breaks down the $22 \%$ of responses by industry, illustrating that this is a significant area of focus for the Education, Business Consulting and Management, Engineering and Manufacturing, and Accountancy, Baking and Finance sectors in particular.

Figure 5

\section{Industries focusing on digital solutions post COVID-19}

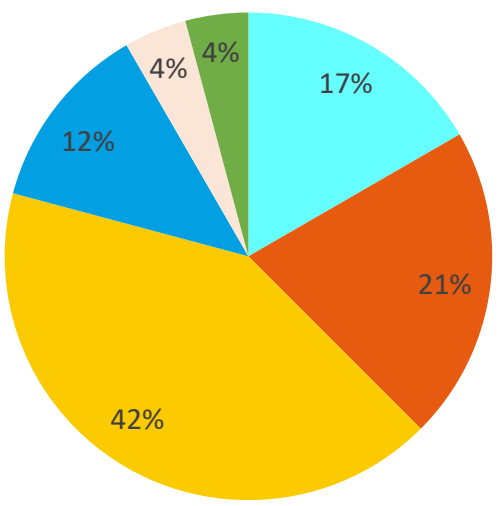

Accountancy, banking and finance

Business, Consulting and Management

Education

- Engineering and Manufacturing

Healthcare

Companies will be investing a significant amount of money in upgrading their IT infrastructure. This inference correlates with the responses received from professionals working within the Information Technology (IT) industry, where 57\% of respondents did not feel that their business had been negatively affected by the Coronavirus. Many IT professionals see the pandemic as an opportunity rather than a threat. COVID-19 has forced us to the adoption of new ways of working, with a significant shift to online solutions. When participants were asked which changes they might adopt more permanently post COVID-19, the most popular category selected was "optimised use of technology", with responses to this category coming from almost all sectors. The second highest response category was "flexible working" which is heavily reliant on robust technological solutions. Technology has been a dominant theme throughout the survey and is clearly a primary agenda for most industries. See chart below. Please note that respondents were able to select more than one category in response to this question. 
Figure 6

\section{COVID-19 has forced us into adoption of new ways of working. Which of these changes might you adopt more permanently post COVID-19?}

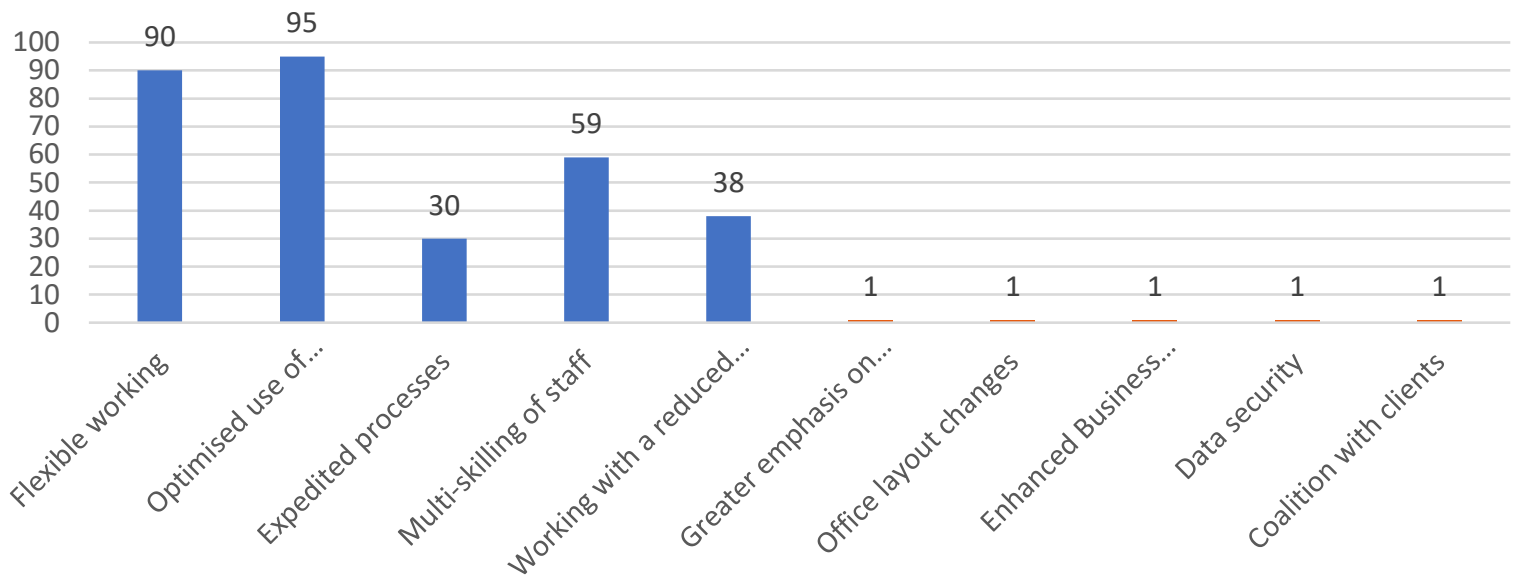

The Government should consider providing support towards technological advancements across the country. This could come in the form of providing investment funds towards new technology start-ups and innovations or extending the existing R\&D tax incentives to include a wider technological scope. Furthermore, small businesses may require financial support to enable them to invest in digital solutions and improved IT infrastructure to remain competitive and relevant.

Rapid response to consumer trends - $100 \%$ of respondents from the Retail sector responded 'yes', their business has been negatively affected by the Coronavirus. The pandemic has accelerated change in shopping habits for the retail sector as a whole, with an increase in online shopping and companies such as Amazon debuting as the big winners. It had also exacerbated existing problems faced by the industry that was present long before the virus struck. Consumer confidence and demand has tumbled, resulting in a steep decline in sales. It has already become evident that the high street will look very different once the pandemic is over. Most, if not all, non-food related retailers are currently operating in negative cash flow. During the pandemic alone, we have seen major retailers from the UK such as DW Sports, Bensons for Beds, Harveys Furniture, TM Lewin, Debenhams, Carphone Warehouse, Monsoon, Oasis and Warehouse going into administration with a number of job losses and stores closed permanently. The Government should aim to monitor consumer behaviours intensely and continually and ensure that any response packages respond to these trends. With consumer behaviour evolving at break-neck speed, the Government may find that a series of short-term support packages may serve the public well.

\subsubsection{Measures and support by businesses to rebuild consumer confidence for sustainable growth}

The other key objective we addressed in this survey is to understand how business can rebuild consumer confidence both economically and environmentally for sustainable growth. To address this point, we examined existing academic research to identify the most important change in the behaviour of businesses and their stakeholders after any pandemic. We find that the tendency of the economic agents is to save more during the pandemic recovery period which results in low investment in assets by the business (Nandy et al., 2020). We mapped this observation from the literature with our survey response. The response from the survey completely supports the evidence from the literature. Many respondents mentioned that they will focus on financial aspects during the post-COVID-19 period, particularly as so many industries cited that they have been negatively impacted by the pandemic, inferring that many are now working with tighter budgets.

Of 122 respondents, 86\% responded 'yes' when asked if they will manage their customers in a different way post-COVID-19. It is evident from the survey results that organisations actively seek ways to help customers in this time of crisis and are being sensitive to their customers' needs. Many industries, such as Marketing, Advertising and PR, are changing tact and priorities to rebuild consumer confidence. Priorities have changed; therefore marketing and sales strategies need to reflect these. A number of businesses have driven the promotion of their brands through waiving subscription fees or offering free services during the pandemic. Whilst this strategy has seen an increase in uptake and consumer engagement, many businesses don't see this as a long-term strategy and cannot afford to continue offering freebies. The Government may find that further financial support may be sought from businesses in the near future to support business development. 
A challenge brought to light by COVID-19 is how businesses can reach out to all their customers and re-build consumer confidence across all populations. For example, the move to increased digitalisation during the pandemic has arguably 'left behind' the older generation who do not all have access to online services. It is promising to see the response plans implemented by some organisations, including NatWest, who are growing their team of Community Bankers whose sole purpose is to reach out to the community and support them with understanding how to manage their finances securely and safely; and Lloyds Bank who decided to give away thousands of tablet devices to the over-70s to help vulnerable customers stay connected during the lockdown. Appreciation for the impact the move to digitalisation will have on customers is manifested in the survey results, with some noting that it will need "patience and temperance for customers and us as well". This statement highlights the magnitude of the changes and associated impacts on everyone involved - it will not be an easy transition for anyone. The Government should investigate inclusive support packages that cater to different populations of race, age and sex. The Government may find that a 'one size fits all' solution is not suitable and that a series of more tailored support packages are required.

Understanding what Customers want and responding to these changing needs is essential to a sustainable recovery process. For example, customers demand more flexible cancellation policies, safer pre-arrival registration processes with minimal personal contact, increased cleaning standards and frequencies in all public buildings, etc. The Government need to strike the "right" balance between supporting consumer rights and supporting businesses in meeting consumer expectations with more flexible policies and access to valuable resources. Based on the evidence from the literature and the responses of the survey, there is a clear indication that the Government should consider all industries when they plan for the provision of support to businesses to rebuild their confidence in the post COVID-19 period.

\subsubsection{Priority to environmental goals}

Because of the higher importance of environmental issues and the contribution of business in developing a sustainable future, we consider the priority of environment goals by the business in their future agenda (Addison et al., 2019). Only 2\% of respondents mentioned that they would prioritise sustainability and the environment most after COVID-19. When all survey participants were explicitly asked if they are planning for any improvement in their sustainability approach post-Covid-19, $79 \%$ responded "yes" and 13\% said "no". A breakdown of responses to this question is illustrated in the graph below.

Figure 7

\section{Are you planning for any improvement in your sustainability approach post Covid-19?}

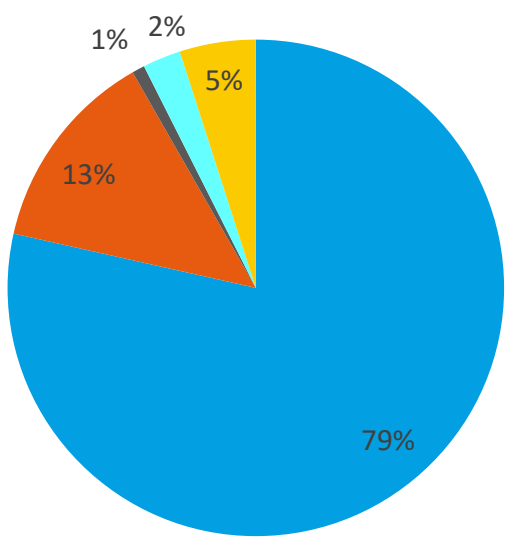

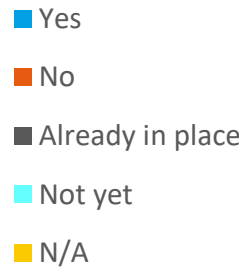

We found that respondents are aware of the possible restricted resources during the post-COVID-19 era and that they are trying to utilise the available resources optimally to be sustainable in the future. There were mixed responses regarding the sustainability approach that businesses are planning to take. This is an area that the Government should prioritise and support through better guidance and clarity over national goals. The Government should consider implementing mandatory environmental measures to help drive behaviours and shape sustainability plans. Promoting cycling and walking is also an agenda that the Government is able to influence and push. 


\subsubsection{Retain key skills and reskill and upskill the workforce}

In this survey we try to understand what any Government can do to support the workforce for sustainable growth and how they can make the country more resilient from future shocks of similar nature.

Solving problems is an immense challenge for businesses, especially during these unprecedented times. If problems are left to fester without due attention, businesses will see damaging effects to their short and long term performance. The rapidly evolving COVID-19 crisis has forced organisations to implement short term fixes and change their approach to internal and external operations. $\mathrm{Cl}$ Projects has experienced first-hand the impacts of change on workforces and stakeholders of the business. Resistance to change is inevitable and should be anticipated; however, during the pandemic, we have seen changes expedite with employee adoption and utilisation rates greater than ever before because people have had no choice but to change. However, the stress caused by this and the uncertainty at work cannot be underestimated. As the agents of the economy are negatively affected, there is evidence of stress in work. In the pre-COVID-19 period, we find evidence that distraction is a common measure to deal with stress in work (Dewe and Guest 1990). But the pandemic erased the option of distraction, which has magnified the problem associated with the well-being of stakeholders. We followed the Effort Recovery Model (ERM) (Meijman and Mulder,1998), which is common in recovery research. To contribute to economic growth, every agent of the economy needs energy and effort to complete the allocated task even in the post crisis period. To perform with high levels of productivity, stakeholders of the business need to recover from the physiological and psychological strain created by the COVID19 pandemic. Because of the lack of sustainable business models, we observed that associates of businesses are busy adapting changes imposed by the pandemic rather than building in 'non-work' time into their schedule. Business stakeholders must take breaks from work because a lack of psychological detachment will decrease productivity. Similarly, any delay in the rebuilding of resources in the recovery period will enlarge the feeling of misfits among stakeholders (Siltaloppi, Kinnunen, Feldt et al. 2011).

The respondents of the survey have suggested that they expect that their business will grow in the next two years. See responses to this question illustrated in the graph below.

Figure 8

\section{How confident are you that your business will grow in the next 2 years?}

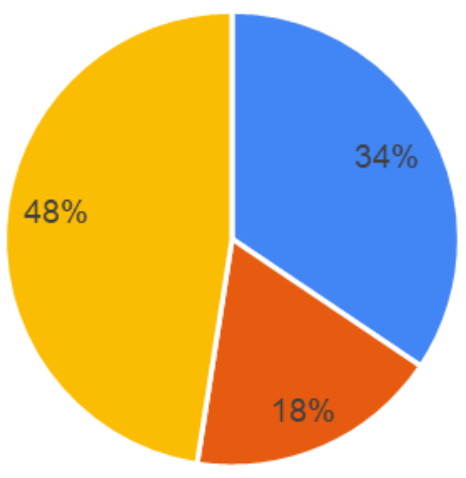

- Very confident

- Not confident

- Fairly confident

Thus, to support the positive thinking economic agents, the Government should make it compulsory for the business to introduce work down-time for their workforce (Sonnentag 2001) during the recovery period to successfully apply the P-E fit model in practice which is observed as the main challenge by many researchers (Bhuiyan, Sakib, Pakpour et al. 2020).

Businesses need to conduct problem-solving activities with their sight on the longer term ramifications of not resolving root causes, and they must do this with a strong focus on change management and employee wellbeing in order for the economy to grow. From the multidimensional survey answers received, we understand that to enhance the contribution of business towards economic growth, every unit of the economy should identify the latitude that allows them to make maximum changes in the system. Such models are capable in solving critical problems, especially by reducing the resistance to change in the complicated situation (Walker, Holling, Carpenter et al. 2004).

There is strong evidence throughout our survey responses that suggest that problem-solving and driving efficiencies will be essential to driving economic growth. For example, it is clear that customer requirements have significantly evolved during the 
pandemic and will continue to do so at a rapid speed. Every business must provide first-class service, operate with efficient processes, minimise waste and overheads and continually monitor consumer behaviours to remain relevant. Customer standards have drastically risen and as a result, consumers are less patient than ever before. One bad experience will turn them away and they will go elsewhere to spend their money; therefore, it is crucial that harmful errors are avoided. Eliminating errors through error-proofing methods, known as Poke Yoke in lean terms, is essential. It is important for businesses to capture, analyse and respond to the 'Voice of the Customer' on a continual basis; a concept central to Lean thinking.

Both speed and quality are essential to business success; therefore, increasing the quality of outputs through reducing defects, compressing order-to-delivery process cycle times and creating value for customers through eliminating waste is the only way organisations will succeed. The application of lean principles will support an operating model that delivers more value with fewer resources, something that every industry has highlighted as a necessity in the survey results. Lean Six Sigma, traditionally used in Manufacturing, will be a key enabler to sustainable recovery. It is therefore recommended that Lean and Six Sigma Principles form part of any upskilling initiatives run by the Government.

Thus, to reset the economy, the Government should assist businesses by providing them training to identify the latitude that will allow the business to incorporate maximum changes without exacerbating the vulnerability of businesses and their stakeholders, who are negatively impacted by COVID-19. Usually, a quick recovery is only possible when economic agents start feeling recovered because of increased resources (Binnewies, Sonnentag and Mojza et al. 2009). However, in the recovery period, even when the resources are limited, the Government can upskill the business to create a sense of recovery.

\section{Conclusion}

\subsection{Academic Conclusion}

To make a country more resilient from any future shock, the Government can apply a revised resilience model which will allow the economy to survive, cope and thrive in future (Tang, 2020). The proposed resilience model will enhance the interaction among the economic agents and can assist the government in rebuilding the economy in the COVID-19 recovery period. In doing so, the main problem with the existing resilience models is the applicability of the same at organisation level. To overcome the mentioned limitation, Tang (2020) expands the resilience model by including an exhaustion and competition element which can assist the Government to direct businesses to apply these during the recovery period.

Figure 9

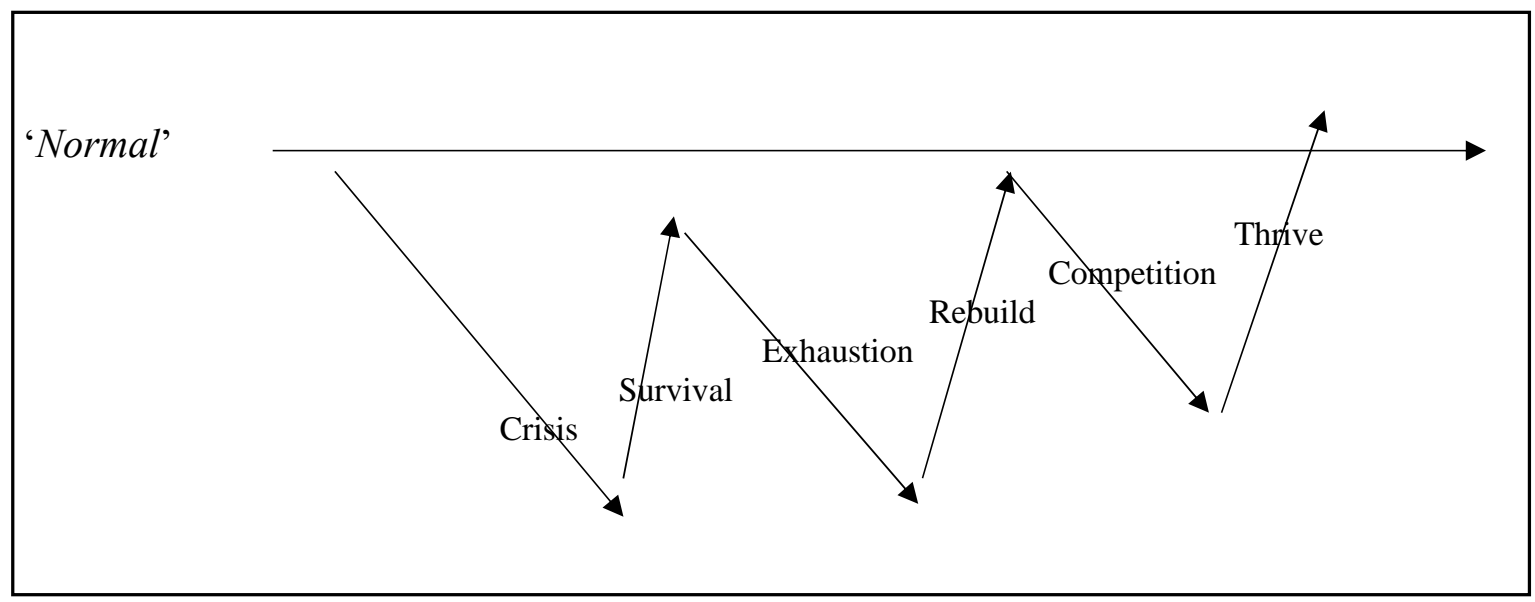

Source: Tang (2020)

By applying the proposed resilience model, the Government can assist businesses to identify their capacity to change and adapt to the new "normal" without disturbing the core activities. At the thriving stage, the model focuses on the 'Panarchy ', which helps the Government to understand how to regulate business competition to thrive during the recovery period. In summary, we recommend that the government should apply the 'emancipator approach' for economic growth in the post-pandemic period and also generate a resilient economy.

\subsection{Business/Professional Conclusion}

In this research, we examined some of the key concerns faced by businesses from various industries which are associated with the COVID-19 pandemic. Over the past 9 years, CI Projects has been working with organisations across a variety of industries to 
help them deliver efficiencies, add more value to their customers and drive a "Continuous Improvement" culture amongst workforces through the application of Lean Six Sigma methods and principles. They have a strong understanding of the key drivers towards sustainable economic recovery and employee wellbeing, having experienced first-hand the success factors that make businesses strive and the poor practices that result in companies collapsing. They have in-depth knowledge of developments in sectors and this has been further validated by the results from the survey and the academic research that supports it. The findings of the survey are supported by literature (Haq and Davies, 2020). Immediate efforts need to be focused on people and operations; this is what extrapolated from our findings and our recommendations are based on these two elements. There is confidence amongst business stakeholders that they will grow within the next 2 years, as cited in the survey responses; however, in order to achieve this, transformational changes will be required in the way they operate, the services and products they deliver, the technological infrastructure they use and the way they manage and optimise their workforce to generate greater value. Going forward, we believe that the application of Lean principles is vital in maximising economic growth and would welcome supporting the government in driving this agenda forward. Based on the findings of the study, we propose that following the above process, we can observe a sustainable growth of the economy. Further research should be conducted on the link between lean and environmental sustainability to achieve a sustainable business that supports the economy and the planet. Figure 10 gives an indication about how the global economy developed after the financial crisis of 2008 and also gives a sign of sustainable development in the post pandemic period.

Figure 10

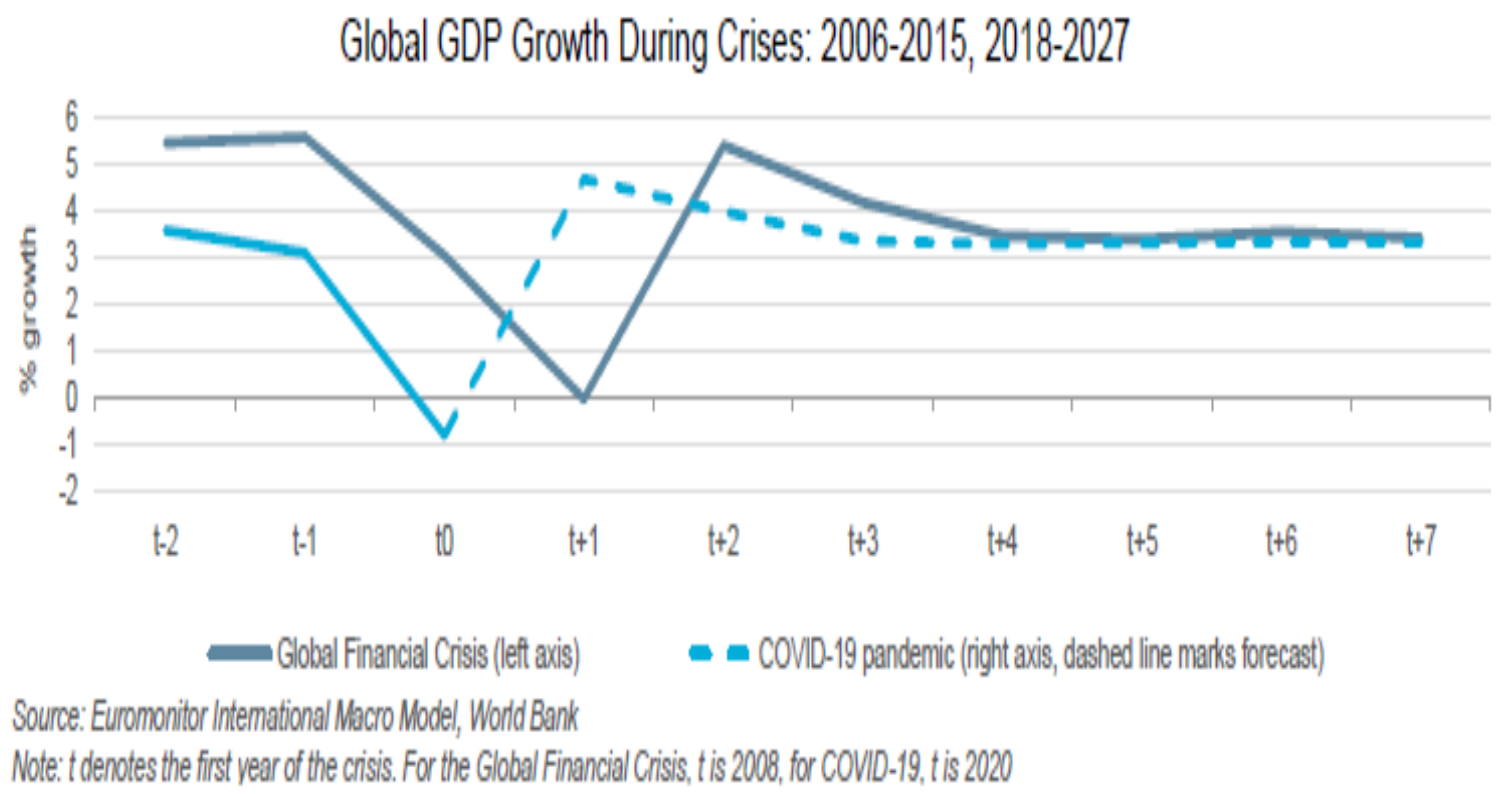

Source: Passport Economic Outlook

Funding: Please add: "This research received no external funding"

Acknowledgements: We would like to thank the team members of the Continuous Improvement Projects Ltd; participants who took part in the survey and Ms. Gurnam Selvarajah from Co-innovative Journey, Brunel University London

Conflicts of Interest: "The authors declare no conflict of interest." 


\section{References}

[1] Acharya, V., R. Engle, and M. Richardson. (2012). Capital shortfall: A new approach to ranking and regulating systemic risks. American Economic Review Papers and Proceedings, 102, .59-64.

[2] Addison, P. F. E., Bull, J. W., and Milner-Gulland, E. J. (2019). Using conservation science to advance corporate biodiversity accountability. Conservation Biology, 33(2), 307-318.

[3] Bailey, C., Madden, A., Alfes, K., and Fletcher, L. (2017). The meaning, antecedents and outcomes of employee engagement: A narrative synthesis. International Journal of Management Reviews, 19(1), 31-53.

[4] Bhuiyan, Al., Sakib, N., Pakpour, A., Griffiths, M.D., and Mamun, M.A. (2020). COVID-19- related suicides in Bangladesh due to lockdown and economic factors: case study evidence from media reports. International Journal of Mental Health Addict, May 15, 1-16.

[5] Binnewies, C., Sonnentag, S., and Mojza, E.J. (2009). Feeling recovered and thinking about the good sides of one's work. Journal of Occupational Health Psychology, 14, 243-256.

[6] Cull, R., and Peria, M. S. M. (2013). Bank ownership and lending patterns during the 2008-2009 financial crisis: Evidence from Latin America and Eastern Europe. Journal of Banking and Finance, 37(12), 4861-4878.

[7] Haq, M and Davies J. (2020). The person with maximum knowledge will win the race": Conceptualizing knowledge in microbusinesses. Journal of Small Business Management, https://doi.org/10.1080/00472778.2020.1768799.

[8] Jaworski, B., Kohli, A. K., and Sahay, A. (2000). Market-driven versus driving markets. Journal of the Academy of Marketing Science, 28(1), 45-54.

[9] Jorda, O., Singh, S. R., and Taylor, A. M. (2020). Longer-run economic consequences of pandemics (Report no. w26934). National Bureau of Economic Research.

[10] Meijman, T.F., and Mulder, G. (1998). Psychological aspects of workload. In P. J. D. Drenth \& C. J. de Wolff (Eds.), Handbook of work and organizational psychology,: Work psychology (pp. 5-33). Hove, UK: Psychology Press.

[11] Nam, T. (2019). Technology usage, expected job sustainability, and perceived job insecurity. Technological Forecasting and Social Change, $138,155-165$.

[12] Nandy, M., Lodh, S., Kaur, J and Wang, J. (2020). Impact of directors' networks on corporate social responsibility: A cross country study. International Review of Finance Analysis, $72,101601$.

[13] Roubini, N. (2020). Coronavirus pandemic has delivered the fastest, deepest economic shock in history. The Guardian, 25 March 2020 , Available at: https://www.theguardian.com/business/2020/mar/25/coronavirus-pandemic-has-delivered-the-fastest-deepest-economicshock-in-history

[14] Siltaloppi, M., Kinnunen, U., Feldt, T., and Tolvanen, A. (2011). Identifying patterns of recovery experiences and their links to psychological outcomes across one year. International Archives of Occupational and Environmental Health, 84, 877-888.

[15] Sonnentag, S. (2001). Work, recovery activities, and individual well-being: A diary study. Journal of Occupational Health Psychology, 6, 196210.

[16] Tang, A. (2020). The Leader's Guide to Resilience. Pearson \& FT in press.

[17] Thakor, A.V. (2015). The Financial Crisis of 2007-2009: Why Did It Happen and What Did We Learn?. Review of Corporate Finance Studies, 4(2). 155-205.

[18] Walker, B., Holling, C.S., Carpenter, S.R., and Kinzig, A. (2004). Resilience, adaptability and transformability in social-ecological systems. Ecology and Society, 9(2), 5. 